\title{
Anaplastic astrocytoma presenting with simultaneous cranial nerve, brainstem and spinal leptomeningeal metastases
}

\author{
Mark William McCusker, Seamus Looby
}

Department of Neuroradiology, Beaumont Hospital, Dublin, Ireland

\section{Correspondence to} Dr Seamus Looby, seamuslooby@beaumont.ie

Accepted 8 April 2014
CrossMark

\footnotetext{
To cite: McCusker MW, Looby S. BMJ Case Rep Published online: [please include Day Month Year] doi:10.1136/bcr-2014203958
}

\section{DESCRIPTION}

A 54-year-old man presented with a 7-week history of morning headaches and vomiting. He described dizziness and balance problems during the preceding 6 months. Clinical examination revealed bilateral optic disc blurring and bilateral lower limb hyper-reflexia. Contrast-enhanced MRI of the brain (figure 1) and whole spine (figure 2) was performed.

Biopsy of the right temporal lesion established a histological diagnosis of infiltrating WHO grade III anaplastic astrocytoma. The imaging and pathological findings confirmed the diagnosis of leptomeningeal metastases from supratentorial astrocytoma. The patient received palliative chemotherapy and died 3 months after the diagnosis.

Symptomatic leptomeningeal metastasis is an uncommon complication of malignant astrocytoma, usually occuring in the context of disease recurrence or progression. ${ }^{1}$ Initial presentation of astrocytoma with symptomatic leptomeningeal metastases is very rare. $^{2}$

The clinical presentation is non-specific and includes headache, confusion, seizures, papilloedema, meningism and multifocal neurological signs including cranial nerve palsies. Spinal leptomeningeal metastases may cause back pain and signs of myelopathy or polyradiculopathy. ${ }^{2}$
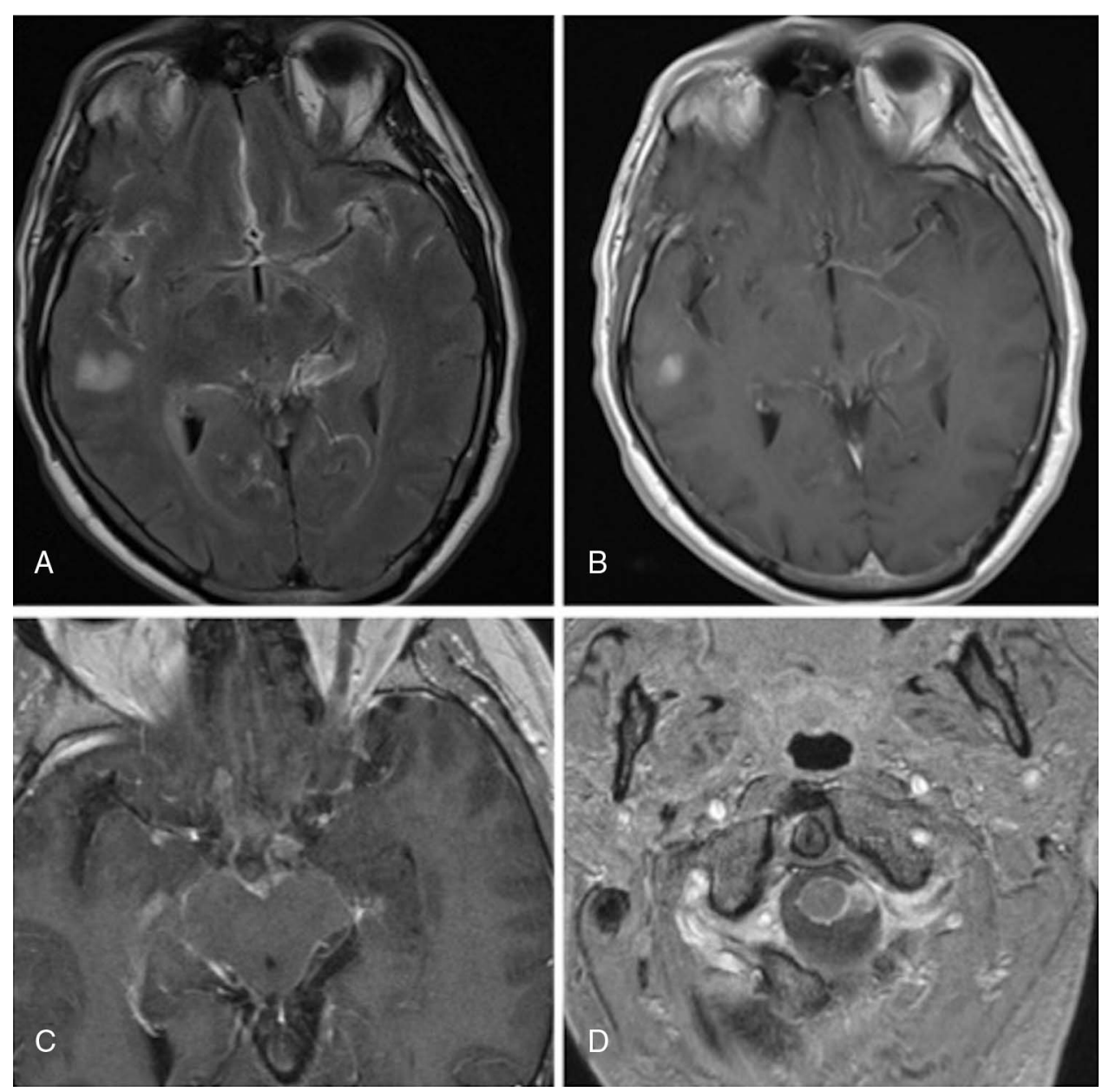

Figure 1 Axial fluid-attenuated inversion recovery (A) and postcontrast T1-weighted (B) images demonstrate diffuse abnormal hyperintensity and leptomeningeal enhancement in the interhemispheric fissure, both sylvian fissures, and several cortical sulci. There is an enhancing intra-axial nodule in the right temporal lobe. Postcontrast axial T1-weighted images at more inferior levels demonstrate leptomeningeal enhancement overlying the midbrain, thickening and enhancement of both oculomotor nerves (C) and leptomeningeal enhancement contiguous with an enhancing nodule at the cervical cord (D). 
Figure 2 Postcontrast T1-weighted sagittal images of the cervicodorsal (A) and dorsolumbar (B) spine demonstrate diffuse enhancement of the leptomeninges overlying the ventral surface of the entire cord. There is an enhancing intradural nodule at the level of $\mathrm{L} 3$.
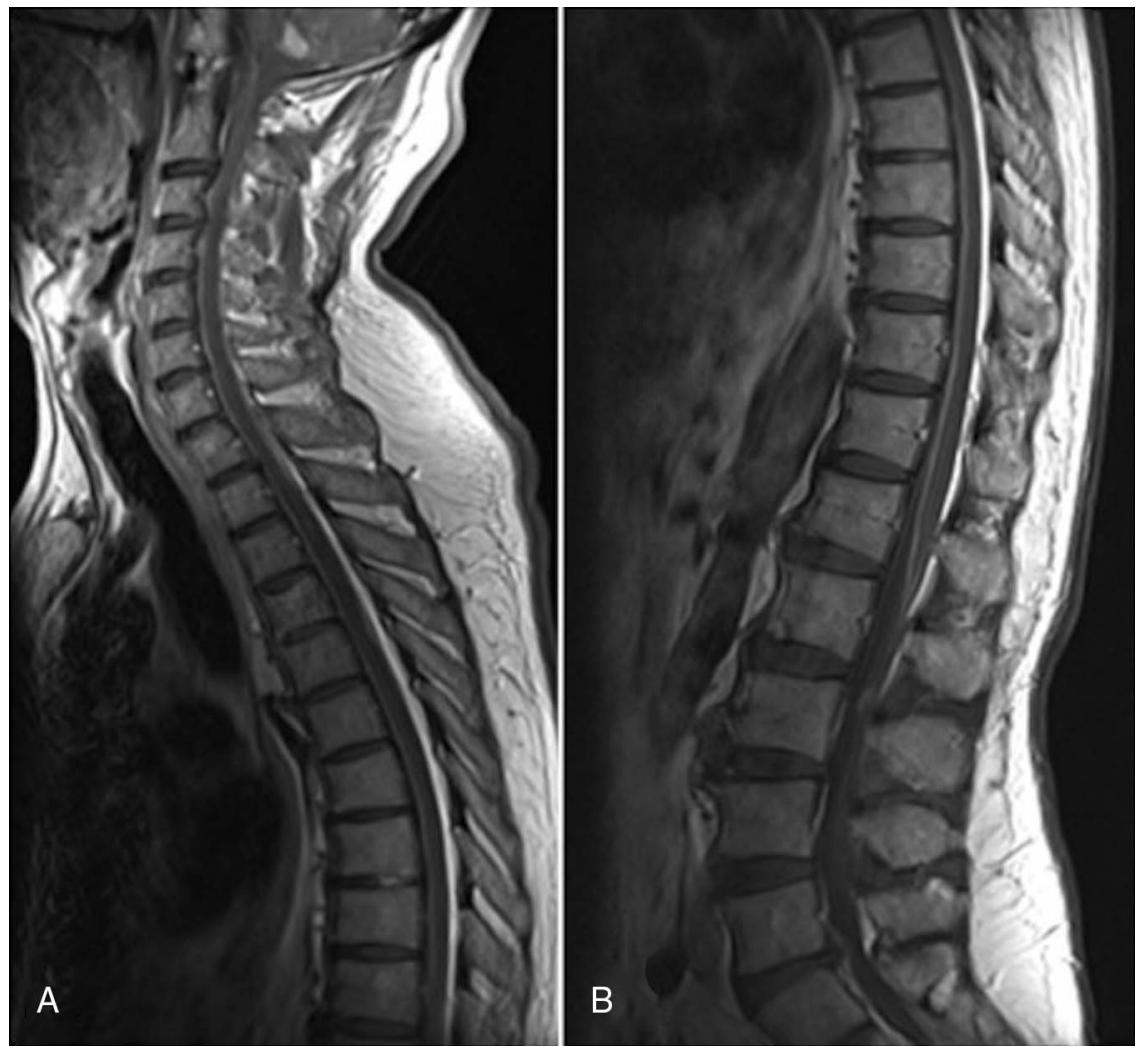

Cerebrospinal fluid cytology is the gold standard for diagnosis but has a false negative rate of up to $50 \% .^{3}$ Contrast-enhanced MRI is more sensitive and frequently establishes the antemortem diagnosis. ${ }^{3}$ Imaging features include pial enhancement (linear over the spinal cord, nodular in cerebral sulci, cerebellar fissures and basal cisterns), cranial and spinal nerve enhancement and communicating hydrocephalus. Conditions that mimic leptomeningeal metastasis include infectious meningitis,

Learning points

- Leptomeningeal dissemination is a rare complication of malignant astrocytoma.

- Cerebrospinal fluid cytology is the gold standard for antemortem diagnosis, but is less sensitive than contrast-enhanced MRI.

- MRI features include pial enhancement, cranial and spinal nerve enhancement and communicating hydrocephalus. neurosarcoidosis, cerebral infarction or recent neurosurgical intervention. $^{3}$

No established therapeutic strategy exists. ${ }^{4}$ The prognosis is universally poor: few patients survive 8 months after diagnosis of leptomeningeal disease. ${ }^{1}$

Contributors Both the authors contributed significantly to this submission. Both the authors encountered the case in clinical practice. MWM drafted the manuscript. SL critically revised the manuscript for content.

Competing interests None.

Patient consent Obtained.

Provenance and peer review Not commissioned; externally peer reviewed.

\section{REFERENCES}

1 Saito $\mathrm{R}$, Kumabe $\mathrm{T}$, Jokura $\mathrm{H}$, et al. Symptomatic spinal dissemination of malignant astrocytoma. J Neurooncol 2003;61:227-35.

2 Wheen LC, Anderson NE, Baker PC, et al. Leptomeningeal infiltration as the presenting manifestation of a malignant glioma. J Clin Neurosci 2006;13:298-301.

3 Collie DA, Brush JP, Lammie GA, et al. Imaging features of leptomeningeal metastases. Clin Radiol 1999;54:765-71.

4 Nandipati S, Demopoulos A. Leptomeningeal dissemination of anaplastic glioma: prolonged survival in two patients treated with temozolomide. J Neurooncol 2011;105:663-5. 
Copyright 2014 BMJ Publishing Group. All rights reserved. For permission to reuse any of this content visit http://group.bmj.com/group/rights-licensing/permissions.

BMJ Case Report Fellows may re-use this article for personal use and teaching without any further permission.

Become a Fellow of BMJ Case Reports today and you can:

- Submit as many cases as you like

- Enjoy fast sympathetic peer review and rapid publication of accepted articles

- Access all the published articles

- Re-use any of the published material for personal use and teaching without further permission

For information on Institutional Fellowships contact consortiasales@bmjgroup.com

Visit casereports.bmj.com for more articles like this and to become a Fellow 